\title{
Evaluation of balance, fall risk, and related factors in patients with fibromyalgia syndrome
}

\author{
Köksal Sarıhan (1), Hülya Uzkeser $@$, Akın Erdal@ \\ Department of Physical Medicine and Rehabilitation, Atatürk University Faculty of Medicine, Erzurum, Turkey
}

Received: March 19, 2020 Accepted: August 26, 2020 Published online: December 01, 2021

\begin{abstract}
Objectives: In this study, we aimed to evaluate whether fibromyalgia patients had a higher fall risk compared to healthy individuals and to identify its relationship, if there was an increase, with clinical features.

Patients and methods: Between March 2018 and September 2018, a total of 50 consecutive female patients with fibromyalgia (median age: 35 years; interquantile range [IQR], 27 to 40 years) and 50 healthy female volunteers (median age: 30 years; IQR, 23 to 40 years) were included in the study. Pain was evaluated with the Visual Analog Scale (VAS), life quality with the Nottingham Health Profile (NHP), balance functions with the Berg Balance Test (BBT), and the risk of falls with a posturography device. Disease activity of fibromyalgia patients was evaluated with the Fibromyalgia Impact Questionnaire (FIQ).

Results: The mean fall risk index of the fibromyalgia patients was $45 \%$. The fall risk index was significantly higher ( $\mathrm{p}=0.010)$ and the BBT scores were significantly lower in the patient group $(\mathrm{p}<0.001)$. There was a significant difference in terms of fall risk between the control group and drug-free fibromyalgia patients; however, no significant difference was found between the balance scores of the two groups. In the fibromyalgia group, a weak positive relationship was determined between the fall risk index and the social isolation subscale of the NHP.

Conclusion: Our study results showed an increased risk of loss of balance and falls in fibromyalgia patients, compared to healthy individuals. This fall risk increase was also detected in fibromyalgia patients who did not use drugs. These findings suggest a possible relationship between social isolation and an increased risk of falls.
\end{abstract}

Keywords: Balance, fall risk, fibromyalgia.

Fibromyalgia syndrome (FMS) is a chronic, rheumatic disease, characterized by widespread pain, sensitive points, disrupted sleep quality, and many additional symptoms. ${ }^{[1,2]}$ It may be seen at all ages and in both sexes; however, its incidence peaks is in the fourth to sixth decades of life. ${ }^{[3]}$ Although there are many different data related to the prevalence of FMS, it is estimated to affect 10 to $15 \%$ of the general population. ${ }^{[4]}$
Recent studies have shown a wide range of abnormalities in the etiology of FMS, such as genetic structure, the autonomous nervous system, neuroendocrine hormones, oxidative stress, central and peripheral nerve system structures, endothelial changes and changes in muscle structures. ${ }^{[5-8]}$ The general evidence is that the etiology is multifactorial.

Balance is a complex process including multidirectional input (somatosensorial, visual and

Corresponding author: Köksal Sarıhan, MD. Atatürk Üniversitesi Tıp Fakültesi Fiziksel Tıp ve Rehabilitasyon Anabilim Dal, 25240 Yakutiye, Erzurum, Türkiye. e-mail: koksalsarihan@hotmail.com 
vestibular) integration to implement neuromuscular activity appropriate to what is required for the maintenance of postural stability. ${ }^{[9]}$ In recent publications related to FMS, balance problems and falls have been reported to be widespread problems in these patient groups. ${ }^{[10-12]}$ In the majority of FMS patients, balance problems are the symptoms that most affect the daily life. ${ }^{[11]}$

Impaired balance and associated falls are serious situations that have a negative effect on the quality of life, with more in some age groups, some disease groups, and may even be fatal. ${ }^{[13-15]}$ More than one-third of adults aged 65 years and over fall each year and, in 20 to $30 \%$ of them, problems may be seen such as hip fractures or head trauma, leading to serious morbidity and mortality. ${ }^{[13]}$

There is a very limited number of studies evaluating the dynamic and static balance together in fibromyalgia patients. In addition, the number of studies evaluating the balance functions in patients with middle age fibromyalgia is quite low. In the present study, we aimed to evaluate whether FMS patients had a higher fall risk compared to healthy individuals and to identify its relationship, if there was an increase, with clinical features.

\section{PATIENTS AND METHODS}

This cross-sectional study was conducted at Atatürk University Faculty of Medicine, Department of Physical Medicine and Rehabilitation outpatient clinic between March 2018 and September 2018. The study included 50 consecutive female patients (median age: 35 years; interquantile range [IQR], 27 to 40 years) who met the 2016 revised Fibromyalgia Diagnostic Criteria, and 50 healthy female volunteers (median age: 30 years; IQR, 23 to 40 years) who met the study inclusion criteria. The patients diagnosed with FMS were evaluated in respect of pain using the Visual Analog Scale (VAS) and in respect of health status and life quality with the Nottingham Health Profile (NHP), ${ }^{[16]}$ while the Berg Balance Test $(\mathrm{BBT})^{[17]}$ and Tetrax $^{\oplus}$ (Sunlight Medical Ltd., Israel) posturography device ${ }^{[18]}$ were used to assess the risk of falling and balance. The disease activity of the FMS patients was evaluated with the Fibromyalgia Impact Questionnaire (FIQ). ${ }^{[19]}$ Patients having a history of malignancy, having a history of severe trauma to lower extremity or shoulder, previous orthopedic surgery, pregnant or breastfeeding women, having a history of neurological, rheumatic, or degenerative disease that could cause balance problems, those receiving drugs other than duloxetine and pregabalin which could cause balance problems, having severe cardiovascular system or respiratory system disease or morbid obesity were excluded from the study. A written informed consent was obtained from each participant. The study protocol was approved by the Atatürk University Faculty of Medicine Ethics Committee (Date: 15/02/2018, No: $2 / 34)$. The study was conducted in accordance with the principles of the Declaration of Helsinki.

Balance measurement in the clinical environment can be applied in many different ways from simple manual tests to advanced measurements with computer-controlled complex devices. Balance measurement methods can be classified in two main groups: dynamic and static tests. In the current study, the static posturography device as a static test and the BBT as a dynamic test were applied for the evaluation of balance.

The risk of falls was calculated using the Tetrax ${ }^{\circ}$ posturography device. ${ }^{[18]}$ During this test, the subject stands on a platform and pressure sensors perceive patterns of movement in the pressure centers. The pressure center and gravity center are calculated by the device, and with the angles expressed, the risk of falls is calculated for the subject as a value between 0 and 100 at the end of the procedure. The falls risk index (FRI) results are divided into three categories of risk of falls. ${ }^{[18]}$ An FRI score of 0-36 indicates a low level of risk, 37-58 a moderate level, and 59-100 a high level.

\section{Statistical analysis}

The study power analysis and sample size calculation were performed using the $G^{\star}$ Power version 3.1.9.4 software (Heinrich-Heine-Universität Düsseldorf, Düsseldorf, Germany). ${ }^{[14]}$ To obtain a difference of 15 in FRI to be significant, at least 40 patients in both groups at $95 \%$ confidence interval (CI) with $80 \%$ study power were needed $(n=80$ in total). Considering the probability of failure to collect data, 50 participants in each group were recruited $(\mathrm{n}=100$ in total).

Statistical analysis was performed using the IBM SPSS version 20.0 software (IBM Corp., Armonk, NY, USA). Conformity of continuous variable to normal distribution was assessed using the ShapiroWilk test. Data were presented in mean \pm standard deviation (SD), median (min-max) or (IQR; $25^{\text {th }}-75^{\text {th }}$ ), or in number and percentage. In the comparisons of two independent groups, the independent samples t-test and Mann-Whitney $U$ test was used. The Kruskal-Wallis $\mathrm{H}$ test was used to compare more than 
two quantitative variables. The Pearson analysis was used to reveal the correlation between two normally distributed quantitative, continuous variables and Spearman correlation analysis was carried out, when the distribution was not normal. A $p$ value of $<0.05$ was considered statistically significant.

\section{RESULTS}

The demographic features of the participants are summarized in Table 1. No statistically significant difference was found between the FMS patient group and the control group in terms of age, height, or body mass index (BMI) ( $>>0.05)$. However, the VAS scores were statistically significantly higher in the FMS group than in the control group $(\mathrm{p}<0.05)$. In addition, in the FMS group, 16 patients were using medication, while there was no regular drug use in any of the participants in the control group.

The BBT scores were statistically significantly lower in the FMS group than in the control group $(\mathrm{p}<0.05)$. The FRI was statistically significantly higher in the FMS group than in the control group $(\mathrm{p}<0.05)$ (Figure 1). The number of falls within the past 12 months was statistically significantly higher in the FMS group than in the control group $(\mathrm{p}<0.05)$.

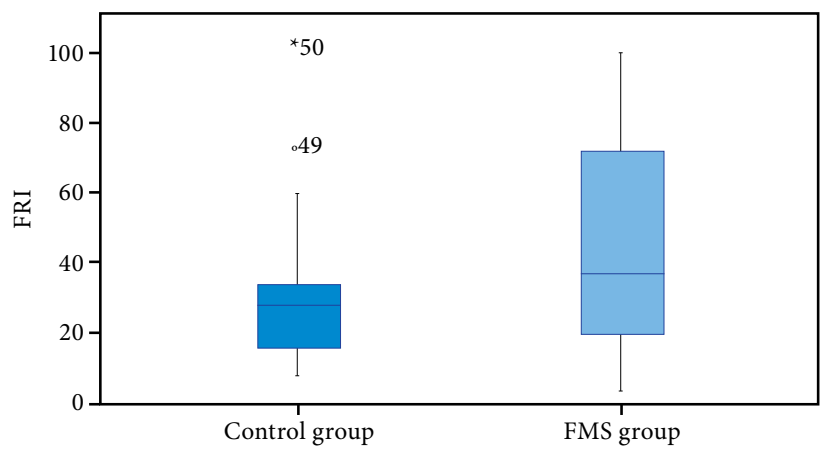

Figure 1. The distribution of FRI in the control and FMS groups.

FRI: Fall Risk Index; FMS: Fibromyalgia Syndrome.

Furthermore, there was significant difference in the FRI between the healthy controls $(n=50)$ and the FMS patients not using medications $(n=34)$. The FRI was statistically significantly higher in the FMS patients not using medication than the healthy control group $(p<0.05)$. However, no difference was found between the BBT scores of the two groups $(\mathrm{p}<0.05)$ (Table 2).

Further comparisons were made within the FMS group between the patients not using any drugs

\begin{tabular}{|c|c|c|c|c|c|c|c|c|}
\hline \multicolumn{9}{|c|}{$\begin{array}{c}\text { TABLE } 1 \\
\text { Demographic characteristics of FMS patients and healthy controls }\end{array}$} \\
\hline & \multicolumn{3}{|c|}{ Control group $(n=50)$} & \multicolumn{3}{|c|}{ FMS group $(\mathrm{n}=50)$} & \multirow[b]{2}{*}{ Test statistics } & \multirow[b]{2}{*}{$p$} \\
\hline & Mean \pm SD & Median & IQR & Mean \pm SD & Median & IQR & & \\
\hline Age (year) & & 30 & $23-40$ & & 35 & $27-40$ & $\mathrm{Z}:-1.416$ & 0.157 \\
\hline Height $(\mathrm{cm})$ & $161.6 \pm 5.8$ & & & $160.8 \pm 5.8$ & & & $\mathrm{t}: 0.567$ & 0.513 \\
\hline Body mass index $\left(\mathrm{kg} / \mathrm{m}^{2}\right)$ & & 24.2 & $21.3-27.7$ & & 25.8 & $22.0-29.5$ & Z: -1.028 & 0.304 \\
\hline Visual Analog Scale (pain) & & 1 & $0-2$ & & 8 & 7-9 & Z: -8.606 & $<0.001$ \\
\hline Berg balance test points & & 51 & $48-52$ & & 47 & $46-50$ & Z:-4.59 & $<0.001$ \\
\hline Fall risk index (\%) & & 28 & $16-34$ & & 37 & $20-72$ & $\mathrm{Z}:-2.59$ & 0.010 \\
\hline Number of falls & & 0 & $0-0$ & & 0 & $0-1$ & $Z: 3.03$ & 0.002 \\
\hline
\end{tabular}

\begin{tabular}{|c|c|c|c|c|c|c|}
\hline \multicolumn{7}{|c|}{$\begin{array}{r}\text { TABLE } 2 \\
\text { Comparisons of FRI and BBT between the control gro }\end{array}$} \\
\hline & \multicolumn{2}{|c|}{ Control group $(n=50)$} & \multicolumn{2}{|c|}{$\begin{array}{l}\text { The FMS patients not using } \\
\text { medication }(\mathrm{n}=34)\end{array}$} & \multirow[b]{2}{*}{ Test statistics } & \multirow[b]{2}{*}{$p$} \\
\hline & Median & IQR & Median & IQR & & \\
\hline Fall risk index (\%) & 28 & $16-34$ & 30 & $20-60$ & Z: -4.072 & $<0.001$ \\
\hline Berg balance test points & 51 & $48-52$ & 47 & $46-50$ & $Z:-1.616$ & 0.106 \\
\hline
\end{tabular}




\begin{tabular}{|c|c|c|c|c|}
\hline \multicolumn{5}{|c|}{$\begin{array}{l}\text { TABLE } 3 \\
\text { The relationships of BBT points and FRI with clinical } \\
\text { features and NHP subscales in FMS group }(n=50)\end{array}$} \\
\hline & \multicolumn{2}{|c|}{ FRI } & \multicolumn{2}{|c|}{ BBT points } \\
\hline & $\mathrm{r}$ & $p$ & $\mathrm{r}$ & $p$ \\
\hline Age & 0.183 & 0.204 & -0.229 & 0.109 \\
\hline Height & -0.040 & 0.787 & 0.037 & 0.800 \\
\hline BMI & 0.203 & 0.170 & -0.330 & 0.024 \\
\hline Disease duration & 0.078 & 0.591 & 0.012 & 0.936 \\
\hline VAS points & -0.146 & 0.311 & -0.012 & 0.933 \\
\hline FIQ points & 0.192 & 0.187 & -0.099 & 0.497 \\
\hline FRI & - & - & -0.808 & $<0.001$ \\
\hline Pain & 0.132 & 0.359 & -0.059 & 0.683 \\
\hline Emotional reaction & 0.102 & 0.482 & 0.003 & 0.986 \\
\hline Sleep & -0.05 & 0.732 & 0.063 & 0.662 \\
\hline Social isolation & 0.287 & 0.044 & 0.245 & 0.870 \\
\hline Mobility & -0.015 & 0.918 & -0.012 & 0.935 \\
\hline Energy & -0.072 & 0.621 & -0.078 & 0.592 \\
\hline NHP Part 1 & 0.118 & 0.416 & -0.046 & 0.749 \\
\hline NHP Part 2 & 0.211 & 0.141 & -0.229 & 0.110 \\
\hline
\end{tabular}

$(\mathrm{n}=34)$, those using duloxetine $(\mathrm{n}=6)$, and those using pregabalin $(\mathrm{n}=5)$. The median FRI was $40 \%$ (IQR: 12-72) in those using duloxetine, 30\% (IQR: 20-60) in those not using any drugs, and 64\% (IQR: 58-80) in those using pregabalin, indicating no statistically significant difference $\left(\chi^{2}=2.831 ; \mathrm{p}=0.243\right)$. The median BBT scores were 49 (IQR: 46-52) in those using duloxetine, 47 (IQR: 46-50) in those not using any drugs, and 47 (IQR: 44-47) in those using pregabalin, indicating no statistically significant difference $\left(\chi^{2}=1.622 ; \mathrm{p}=0.444\right)$.

When all the participants were evaluated, no significant correlation was found between the FRI measured with posturography and age, height or BMI ( $p>0.05)$. However, a weak, negative, but significant correlation was observed between the age and the BBT scores $(\mathrm{r}=-0.291 ; \mathrm{p}=0.003)$ and between BMI and the BBT scores $(\mathrm{r}=-0.247 ; \mathrm{p}=0.013)$. No significant relationship was determined between the height and BBT scores $(r=0.037 ; \mathrm{p}=0.800)$.

In the evaluations of the FMS group, a moderate, negative, and significant correlation was found between the BBT scores and BMI $(r=-0.330 ; p=0.024)$. A strong, negative, and significant relationship was found between the BBT scores and FRI $(r=-0.808$; $\mathrm{p}<0.001)$. However, there was no statistically significant correlation between the other clinical characteristics (p>0.05) (Table 3).

In the evaluations of the FMS group, a weak, positive, but significant relationship was observed between the FRI and the social isolation subscale of the NHP $(r=0.287 ; \mathrm{p}=0.044)$. However, no significant correlation was found between the other subscales of the NHP and the FRI and BBT scores $(\mathrm{p}>0.05)$ (Table 3).

\section{DISCUSSION}

In the present study, we aimed to evaluate whether FMS patients had a higher fall risk compared to healthy individuals and to identify its relationship with clinical features. The results of this study showed that FMS caused an increase in the loss of balance and the risk of falls, as objectively evidenced by a computerized balance system.

Previous studies have shown that FMS can affect the processes related to balance in the body, and may be the cause of patient complaints of balance problems and falls. ${ }^{[20,21]}$ Studies have also revealed that FMS patients have a low confidence in their balance. $^{[22]}$ In an online questionnaire study, $45 \%$ of FMS patients were found to have balance problems, which was concluded to be a widespread complaint. ${ }^{[1]}$ However, the number of studies evaluating the static and dynamic balance together is limited. In addition, drug use has not been evaluated in the majority of studies. In general, balance problems in FMS can emerge associated with impaired nerve system functions, vertigo, pain, impaired sleep quality, and reduced muscle strength and endurance associated with inactivity. ${ }^{[20,21,23]}$ Some authors have shown that the loss of balance in patients diagnosed with FMS is basically the result of the loss of postural control. ${ }^{[12,22]}$ Consequently, the balance defects experienced in this patient group may cause a reduction in functional independence. ${ }^{[2]}$ The results of the current study support the findings of previous studies in FMS patients, and the risk of falls and loss of balance were found to be higher in female patients with FMS. The number of falls in the FMS patient group was also found to be higher than in the control group.

It has been proposed that balance functions can be impaired due to pain. There are studies in the literature supporting this theory, while there are conflicting opinions, as well. ${ }^{[20,25]}$ In the FMS group of the current study, no significant correlation was 
found between the pain levels and the fall risk. Previous studies have also suggested that, as the disease becomes chronic in FMS patients, the postural control mechanisms are weakened through inactivity due to pain, fatigue, and chronic sleep problems. ${ }^{[10,26]}$ Therefore, it can be considered that the duration of the disease may be related to postural instability and an increased risk of falls. However, in the current study, no significant correlation was found between the loss of balance and disease duration. This finding indicates that loss of balance is not associated with the disease duration and level of pain.

According to previous studies, the fall risk and loss of balance increase dramatically with the increasing age. ${ }^{[13,27]}$ When all the participants in the current study were evaluated, no significant relationship was found between age and the FRI. However, we found a negative correlation between the age and BBT scores. The reason that there was no correlation between the age and the FRI, but there was a correlation with the BBT points could be that the BBT is a dynamic measurement and loss of dynamic balance is more evident with ageing. In the current study, there was no significant correlation between the age and the FRI or the BBT scores in the FMS patients. This finding suggests that loss of balance is not associated with age in middle-aged FMS patients.

In a previous study evaluating FMS patients with a balance evaluation system, there was a significant balance impairment in the FMS group, compared to the control group. ${ }^{[20]}$ There was also a significant relationship between the loss of balance and FIQ scores. In another randomized-controlled study, the fall histories of 32 FMS patients were examined, and the clinical characteristics and dynamic balance status were evaluated using the FIQ, BBT, and dynamic posturography. ${ }^{[21]}$ The results showed an increased loss of balance and weak postural control in the FMS patients. There was also a significant relationship between the balance scores and the FIQ results. Similar to these findings in the literature, the current study showed an increased loss of balance in FMS patients. However, unlike the literature, no significant correlation was found between the FRI and the BBT results and the fibromyalgia disease activity.

Several studies have found a relationship between several drugs and impaired balance. ${ }^{[28,29]}$ In a study of FMS patients aged 50 years and over, drug use was associated with the risk of falls. ${ }^{[30]}$ Antidepressants and anti-epileptics, such as pregabalin, are drugs which can particularly cause severe neurological side effects. ${ }^{[30]}$ Drug use was identified as an independent risk factor for balance impairment in another study. ${ }^{[29]}$ In the current study, the patients those using duloxetine or pregabalin had higher FRI than patients not using any drugs, although the difference was not statistically significant. This difference might not have been statistically significant, due to the small number of patients in the FMS group who were using drugs. The FMS patients not using drugs had a significantly greater FRI than the control group and, although the BBT results were different, they were statistically comparable. The main reason for these results could be the loss of static balance of the FMS patients, and another reason could be the low number of patients. Based on these results, we can conclude that static balance is lost, in particular, in FMS patients independently of drug use and there may be an additional contribution of drug use to this loss of balance. Nevertheless, there is a need for further studies on this subject with larger patient groups.

Furthermore, previous studies have shown that balance defects in FMS patients are related to decreased functional independence. ${ }^{[24]}$ In the current study, life quality was evaluated using the NHP. A positive correlation was only observed between the FRI of FMS patients and the social isolation subscale of the NHP. No significant relationship was determined between the BBT scores of the FMS patients and the NHP and the subscale points. These findings indicate that there could be a relationship between balance problems and increased fall risk in FMS patients and social isolation.

The mean FRI of the FMS patients in the current study was approximately $45 \%$. This result suggests that there is a moderate level of fall risk in FMS patients. ${ }^{[18]}$ This information should be communicated to patients diagnosed with FMS and would be extremely useful in increasing treatment compliance. Most of the previous studies related to balance and fall risk have included patients over the age of 50 years. ${ }^{[30-33]}$ The low mean age of the patients in the current study is extremely important in respect of eliminating pathologies which could be age-related, may be overlooked, and which could cause loss of balance. Additionally, in the current study, static and dynamic measurement methods of balance evaluation were used. In these respects, the results of the current study can be considered valuable. 
The relatively low number of patients in the FMS group receiving medical treatment such as duloxetine and pregabalin can be regarded as the main limitation of the present study.

In conclusion, the results of this study demonstrated an increased loss of balance and fall risk in females with FMS, compared to the control group. This fall risk increase was also observed in FMS patients who did not use drugs. In addition, there was a higher number of falls in the FMS patient group than the control group. Also, there could be a relationship between social isolation and an increased risk of falls. Taken together, in FMS patients, it is recommended to be careful about falling and necessary precautions. In addition, there is a need for studies examining the relationship between loss of balance and vestibular dysfunction, sense of proprioception, loss of muscle strength, postural reflexes, hormone levels, orthostatic hypotension, cognitive symptoms, and vitamin deficiency in FMS patients.

\section{Declaration of conflicting interests}

The authors declared no conflicts of interest with respect to the authorship and/or publication of this article.

\section{Funding}

The authors received no financial support for the research and/or authorship of this article.

\section{REFERENCES}

1. Kurtaiş YA. Fibromiyalji sendromu: Editörler: Ataman Ş, Yalçın P. Romatoloji. Ankara: Medikal Nobel Tıp Kitabevi; 2012. s. 755-76.

2. Şendur ÖF, Kahvecioğlu F. Ağrılı kas sendromları: Editör: Oğuz H. Tıbbi Rehabilitasyon. Ankara: Nobel Tıp Kitabevi; 2015. s. 1011-24.

3. İnanıc1 F. Fibromiyalji sendromu: Editörler: Beyazova $M$, Kutsal YG. Fiziksel Tıp ve Rehabilitasyon. Ankara: Güneş Tip Kitabevi; 2011. s. 2365-77.

4. Branco JC, Bannwarth B, Failde I, Abello Carbonell J, Blotman F, Spaeth M, et al. Prevalence of fibromyalgia: a survey in five European countries. Semin Arthritis Rheum 2010;39:448-53.

5. Ozgocmen S, Ozyurt H, Sogut S, Akyol O. Current concepts in the pathophysiology of fibromyalgia: the potential role of oxidative stress and nitric oxide. Rheumatol Int 2006;26:585-97.

6. Martínez-Lavín M, Hermosillo AG. Autonomic nervous system dysfunction may explain the multisystem features of fibromyalgia. Semin Arthritis Rheum 2000;29:197-9.

7. Le Goff $\mathrm{P}$. Is fibromyalgia a muscle disorder? Joint Bone Spine 2006;73:239-42.

8. Bağcier F, Tufanoğlu FH, Kadıçeşme Ö. Is There Any Relationship Between Serum Endocan Levels and Carotid Intima-media Thickness in Patients with Fibromyalgia? Turk J Osteoporos 2019;25:49-52.
9. Horak FB. Postural orientation and equilibrium: what do we need to know about neural control of balance to prevent falls? Age Ageing 2006;35 Suppl 2:ii7-iil1.

10. Meireles SA, Antero DC, Kulczycki MM, Skare TL. Prevalence of falls in fibromyalgia patients. Acta Ortop Bras 2014;22:163-6.

11. Bennett RM, Jones J, Turk DC, Russell IJ, Matallana L. An internet survey of 2,596 people with fibromyalgia. BMC Musculoskelet Disord 2007;8:27.

12. Muto LH, Sauer JF, Yuan SL, Sousa A, Mango PC, Marques AP. Postural control and balance self-efficacy in women with fibromyalgia: are there differences? Eur J Phys Rehabil Med 2015;51:149-54.

13. Tinetti ME, Williams TF, Mayewski R. Fall risk index for elderly patients based on number of chronic disabilities. Am J Med 1986;80:429-34.

14. Alkan Melikoğlu M, Bağcier F. Fall Risk and Related Factors in Systemic Lupus Erythematosus. Arch Rheumatol 2017;32:216-20.

15. Alkan Melikoğlu M, Kul A. Fall risk and related factors in knee osteoarthritis. Turkish Journal of Geriatrics 2018;21:49-55.

16. Madenci E, Gürsoy S, Arıca E, Keven S. The Nottingham health profile assessment of quality of life in patients with primary fibromyalgıa syndrome. Turkiye Klinikleri J PM\&R 2003;3:11-4.

17. Sahin F, Yilmaz F, Ozmaden A, Kotevolu N, Sahin T, Kuran B. Reliability and validity of the Turkish version of the Berg Balance Scale. J Geriatr Phys Ther 2008;31:32-7.

18. Tetrax Hekim Rehberi, Yazılım Versiyonu 5.0/15.0 DUM 0062 Revision 01. Available at: http://www.caglarmedical. com/tetrax/thr.pdf. [Accessed: October 11, 2019]

19. Sarmer S, Ergin S, Yavuzer G. The validity and reliability of the Turkish version of the Fibromyalgia Impact Questionnaire. Rheumatol Int 2000;20:9-12.

20. Jones KD, Horak FB, Winters-Stone K, Irvine JM, Bennett RM. Fibromyalgia is associated with impaired balance and falls. J Clin Rheumatol 2009;15:16-21.

21. Russek LN, Fulk GD. Pilot study assessing balance in women with fibromyalgia syndrome. Physiother Theory Pract 2009;25:555-65.

22. Jones KD, King LA, Mist SD, Bennett RM, Horak FB. Postural control deficits in people with fibromyalgia: a pilot study. Arthritis Res Ther 2011;13:R127.

23. Akkaya N, Akkaya S, Atalay NS, Acar M, Catalbas N, Sahin F. Assessment of the relationship between postural stability and sleep quality in patients with fibromyalgia. Clin Rheumatol 2013;32:325-31.

24. Pérez-de-Heredia-Torres M, Huertas-Hoyas E, MartínezPiédrola R, Palacios-Ceña D, Alegre-Ayala J, SantamaríaVázquez $\mathrm{M}$, et al. Balance deficiencies in women with fibromyalgia assessed using computerised dynamic posturography: a cross-sectional study in Spain. BMJ Open 2017;7:e016239.

25. Ulus Y, Akyol Y, Tander B, Durmuş D, Bilgici A, Kuru Ö. Is there a balance problem in hypermobile patients with fibromyalgia? Turk J Rheumatol 2013;28:10-5.

26. Watson NF, Buchwald D, Goldberg J, Noonan C, Ellenbogen RG. Neurologic signs and symptoms in fibromyalgia. Arthritis Rheum 2009;60:2839-44. 
27. Tinetti ME. Clinical practice. Preventing falls in elderly persons. N Engl J Med 2003;348:42-9.

28. Tinetti ME, Doucette JT, Claus EB. The contribution of predisposing and situational risk factors to serious fall injuries. J Am Geriatr Soc 1995;43:1207-13.

29. Boyle N, Naganathan V, Cumming RG. Medication and falls: risk and optimization. Clin Geriatr Med 2010;26:583-605.

30. Rutledge DN, Cherry BJ, Rose DJ, Rakovski C, Jones CJ. Do fall predictors in middle aged and older adults predict fall status in persons 50+ with fibromyalgia? An exploratory study. Res Nurs Health 2010;33:192-206.
31. Kasapoğlu Aksoy M, Altan L, Ökmen Metin B. The relationship between balance and vitamin $25(\mathrm{OH}) \mathrm{D}$ in fibromyalgia patients. Mod Rheumatol 2017;27:868-74.

32. Nitz JC, Choy NL, Isles RC. Medial-lateral postural stability in community-dwelling women over 40 years of age. Clin Rehabil 2003;17:765-7.

33. Naessen T, Lindmark B, Larsen HC. Better postural balance in elderly women receiving estrogens. Am J Obstet Gynecol 1997;177:412-6. 